\title{
Deep Atlantic variability during the last interglacial period
}

Eirik V. Galaasen' ${ }^{1}$ U.S. Ninnemann ${ }^{1,2}$, N. Irvalı1, H.F. Kleiven ${ }^{1,2}$ and C. Kissel ${ }^{3}$

\begin{abstract}
A new multi-decadally resolved benthic stable isotope record suggests that the distribution of deep Atlantic water masses experienced large, short-lived changes during the Last Interglacial. The findings question the relative stability of deep circulation during times of warmth and ice retreat.
\end{abstract}

One key uncertainty in future climate projections involves changes to the circulation of North Atlantic Deep Water (NADW) and how it responds to buoyancy gain from warmth and freshwater additions in the regions of deep-water formation. Model simulations of Atlantic overturning strength range from nearly no change to $\sim 50 \%$ reduction by 2100 AD (Stocker et al. 2013). Reconstructions of NADW variability during past warm periods provide an opportunity to assess its potential response to conditions similar to those we may face in the future. For example, did NADW respond to the forcing of the last interglacial period (LIG; 115-130 ka) when its source region experienced elevated warmth in the order of $\sim 2-4^{\circ} \mathrm{C}$ and ice mass retreat relative to today (Otto-Bliesner et al. 2006; NEEM community members 2013)? Yes, suggests our ultra-highly resolved stable isotope record generated as part of the Past4Future project.

\section{NADW variability during the LIG}

Galaasen et al. (2014) reconstructed variability in NADW over the LIG using epibenthic foraminifera C. wuellerstorfi $\delta^{13} \mathrm{C}$ from the Eirik Drift (Fig. 1). This foraminifera records the ambient bottom water $\delta^{13} \mathrm{C}$ in its shell (e.g. Duplessy et al. 1984), hence it can be used to map out the distribution and circulation of water masses in the Atlantic interior (Fig. 1). The rapid sediment accumulation of $\sim 35 \mathrm{~cm} \mathrm{ka}^{-1}$ at the Eirik Drift site allowed us to reconstruct variability in newly formed Lower NADW with a high temporal resolution of $\sim 30$ years.

The Eirik Drift bottom water $\delta^{13} \mathrm{C}$ record indicates that NADW circulation was stable on multi-millennial timescales during the LIG, consistent with previous studies (e.g. Adkins et al. 1997). However, zooming in on shorter timescales reveals that this stable circulation state was interrupted repeatedly as the influence of NADW waned (bottom water $\delta^{13} \mathrm{C}$ decreased; Fig. 2) and Southern Source Water (SSW) advanced to fill the deep Atlantic. These transient

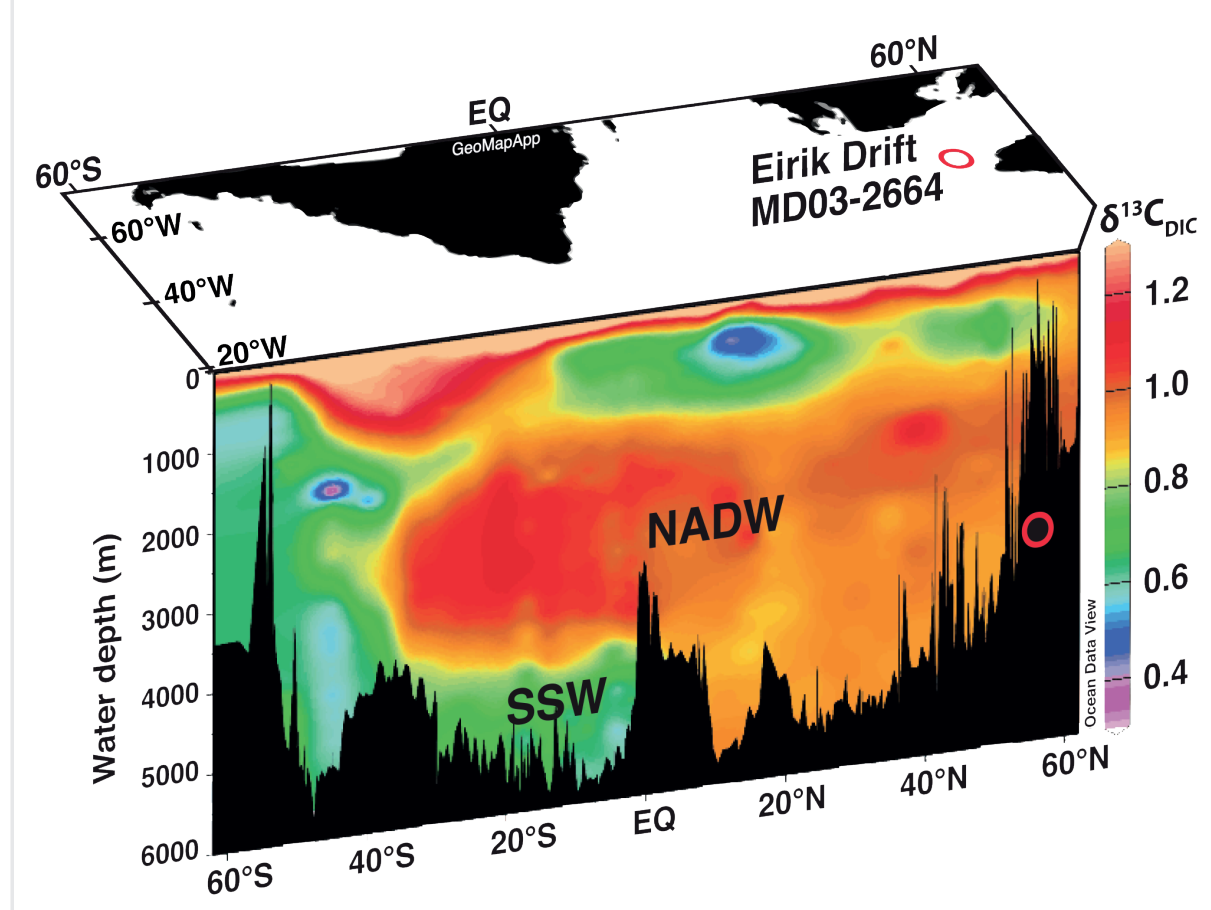

Figure 1: The location of Eirik Drift core site MD03-2664 (red circle: $57^{\circ} 26^{\prime} \mathrm{N}, 48^{\circ} 36^{\prime} \mathrm{W} ; 3442 \mathrm{~m}$ water depth) plotted geographically and projected onto the mid-Atlantic topographic profile. Colors show the modern carbon isotopic composition of dissolved inorganic carbon $\left(\delta^{13} C_{D I C}\right.$; Key et al. 2004). Note the strong influence of high$\delta^{13} \mathrm{C}$ North Atlantic Deep Water (NADW) in the modern Atlantic, overlying low- $\delta{ }^{13} \mathrm{C}$ Southern Source Waters (SSW). Figure modified from Galaasen et al. (2014).

NADW reductions reflect marked shifts in the circulation pattern and spatial geometry of the deep Atlantic, with shoaling of NADW and northward expansion of SSW (Fig. 1). Although difficult to determine precisely, each of these anomalies appears to have lasted several centuries before recovering, operating as if the circulation was near a threshold, but occasionally flickering back and forth across it. A critical question is then, what pushed the circulation towards this threshold and triggered these NADW reductions? Buoyancy gain in the NADW source regions likely played a key role.

The transient NADW perturbations were more pronounced and more frequent around the early part of the LIG interval. This period was characterized by peak Northern Hemisphere warmth (OttoBliesner et al. 2006; NEEM community members 2013) and high input of icebergs (ice-rafted debris (IRD) increases) and freshwater (N. pachyderma (s) Ba/Ca increases) at the sea surface in the Eirik Drift region (Fig. 2). The last and most prominent of the NADW anomalies during the early LIG (at $\sim 124 \mathrm{ka}$ ) was also associated with an outburst flood analogous to the one believed to have triggered the $8.2 \mathrm{ka}$ event, when large amounts of freshwater entered the North Atlantic through the Labrador Sea (Nicholl et al. 2012; Galaasen et al. 2014). Taken together, this highlights buoyancy gain from a generally warm 
background climate and episodic freshwater inputs as the trigger for the transient NADW anomalies of the LIG. Increases in the abundances of $N$. pachyderma (s) in the Eirik Drift core also indicate that each of the NADW anomalies was associated with an increased influence of polar, i.e. cold and fresh surface water (see Galaasen et al. 2014). A similar pattern of repeating and transient polar water expansions during the LIG was also found in the northeastern North Atlantic (Mokeddem et al. 2014). This suggests that the hydrographic surface water anomalies detected at the Eirik drift site might in fact have extended across the subpolar North Atlantic, indicating a strong coupling between surface and deep ocean conditions.

\section{Interglacial NADW instability}

Previous studies have suggested that NADW ventilation was generally suppressed during the early part of the LIG (e.g. Sánchez Goñi et al. 2012). The new high-resolution Eirik Drift record revises this notion, suggesting rather that several centennial-scale NADW changes occurred superimposed on a longer-term stable circulation state that was established at the start of the LIG benthic $\delta^{18} \mathrm{O}$ plateau (e.g. Adkins et al. 1997). However, the dimension of these NADW reductions remains unclear. While apparent in the deepest parts of the northeast (Hodell et al. 2009) and northwest Atlantic (Galaasen et al. 2014), suggesting NADW shoaled, determining how far will require additional constraints from shallower water depths.

High-resolution records of NADW variability are now available for both the Holocene and LIG, providing new insights into the stability of NADW under warm climate conditions. In both interglacials, NADW reductions cluster around the early phase. This suggests that retreating ice masses remnant from the prior glaciation were important triggers for NADW perturbations (Kleiven et al. 2008; Galaasen et al. 2014). Yet, while the Holocene experienced only one substantial perturbation to the ventilation of NADW, associated with the 8.2 ka event (Ellison et al. 2006; Kleiven et al. 2008), the LIG had several more (Fig. 2). Indeed, NADW reductions may not even have been limited to the phase of peak warmth and ice retreat during the early part of LIG. The Eirik Drift data indicate that NADW changes also occurred during the later phases of the LIG (Fig. 2).

Although these variations still need to be replicated using other high-resolution sites, the increased frequency of NADW reductions during the LIG compared to the Holocene may suggest that deep Atlantic ventilation is increasingly vulnerable as its source region warms and freshens beyond today's levels. Further studies, including data-model comparisons and extending high-resolution records to previous interglacials, may help constrain where that potential buoyancy threshold lies and elucidate its full consequences for the circulation of the deep Atlantic.

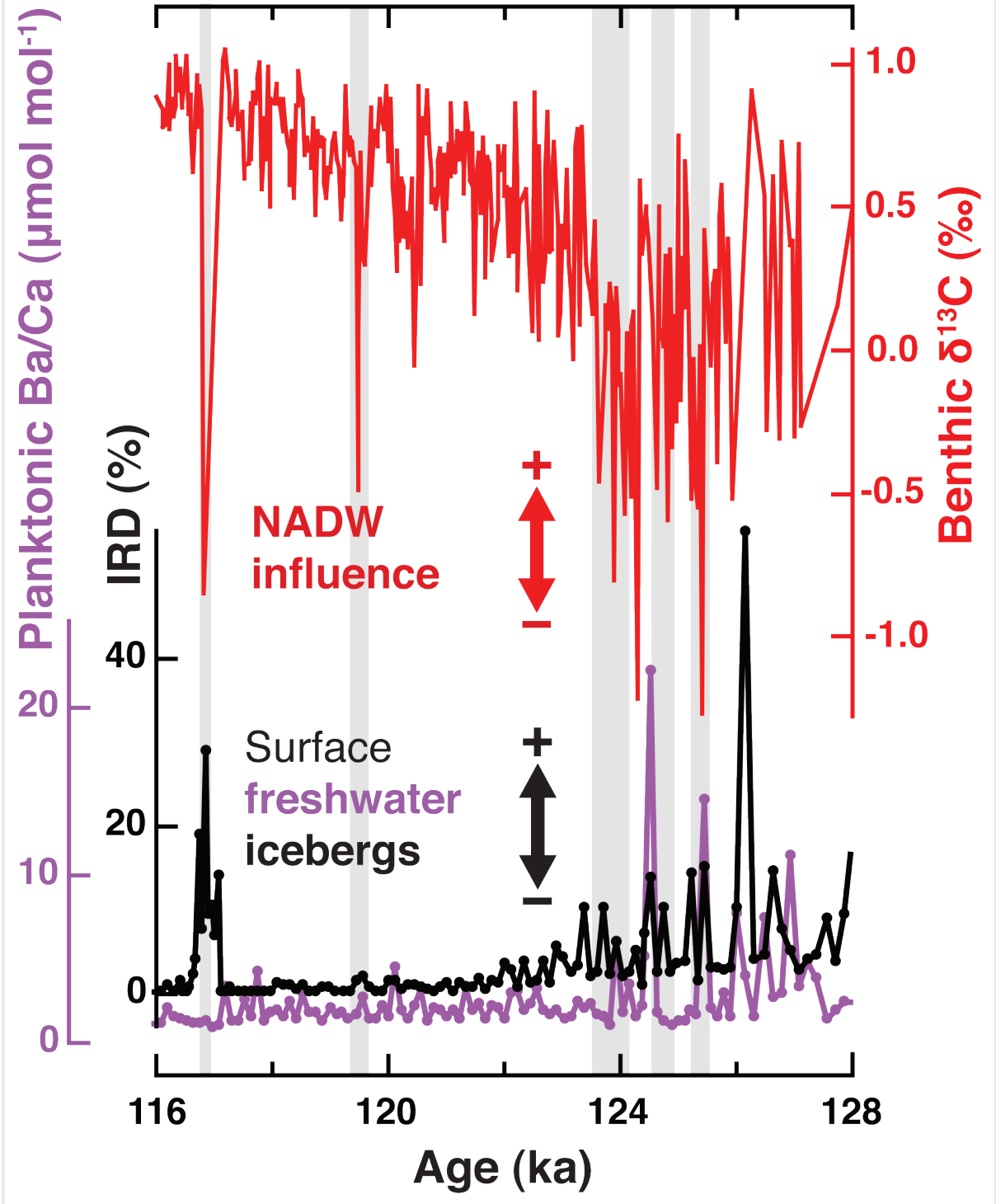

DATA

The Eirik Drift core MD03-2664 epibenthic foraminifera stable isotope data are available as supplementary material to Galaasen et al. (2014).

\section{AFFILIATIONS}

'Department of Earth Science and Bjerknes Centre for Climate Research, University of Bergen, Norway

${ }^{2}$ Uni Climate, Uni Research, Bergen, Norway

${ }^{3}$ Laboratoire des Sciences du Climat et de l'Environnement/IPSL, CEA/CNRS/UVSQ, Gif-sur-Yvette, France

\section{CONTACT}

Eirik V. Galaasen: eirik.galaasen@geo.uib.no REFERENCES

Adkins JF et al. (1997) Nature 390: 154-156

Duplessy JC et al. (1984) Quat Res 21: 225-243

Ellison CRW et al. (2006) Science 312: 1929-1932

Galaasen EV et al. (2014) Science 343: 1129-1132 Hodell DA et al. (2009) Earth Planet Sci Lett 288: 10-19 Stocker TF et al. (2013) Climate Change 2013: The Physical Science Basis. Cambridge University Press, 1535pp

Key RM et al. (2004) Global Biogeochem Cycles 18, doi:10.1029/2004GB002247

Kleiven HKF et al. (2008) Science 319: 60-64 Mokeddem Z et al. (2014) PNAS 111: 11263-11268 NEEM community members (2013) Nature 493: 489-494 Nicholl JAL et al. (2012) Nat Geosci 5: 901-904 Otto-Bliesner BL et al. (2006) Science 311: 1751-1753 Sánchez Goñi MF et al. (2012) Geology 40: 627-630 Shackleton NJ et al. (2002) Quat Res 58: 14-16

Shackleton NJ et al. (2003) Global Planet Change 36: 151-155

Figure 2: Eirik Drift sediment core MD03-2664 records across the LIG, focused on the Marine Isotope Stage 5 e benthic $\delta^{18} \mathrm{O}$ plateau, (116.1-128.0 ka; Shackleton et al. 2002; Shackleton et al. 2003): Red curve: $\delta^{13} \mathrm{C}$ measured on shells of the epibenthic foraminifera $\mathrm{C}$. wuellerstorfi; Purple curve: $\mathrm{Ba} / \mathrm{Ca}$ ratio in shells of the planktonic foraminifera N. pachyderma (s); Black curve: Ice-rafted debris (IRD) percentage in the coarse fraction. Gray shading highlights intervals of reduced bottom water $\delta^{13} \mathrm{C}$ and NADW influence. Figure modified from Galaasen et al. (2014). 